\title{
POWER QUALITY MONITORING AS INTEGRATED WITH DISTRIBUTION AUTOMATION
}

Antti Mäkinen, Marko Parkki and Pertti Järventausta

Tampere University of Technology, Finland
Markus Kortesluoma and Pekka Verho

ABB Substation Automation Oy, Finland
Seppo Vehviläinen

MX Electrix Oy, Finland
Reino Seesvuori

Tampere Power Utility, Finland
Aimo Rinta-Opas

Koillis-Satakunnan Sähkö Oy, Finland

\section{SUMMARY}

Requirements and expectations associated with power quality have been become increasingly important in our modern society. The quality of power distribution includes both power quality and quality of customer services. At the same time with the developments in distribution automation and the electricity market, many practices at electricity distribution companies are changing, and new possibilities and challenges are emerging.

Nowadays, in Finland power quality measurements are usually carried out temporarily, lasting from some few hours to some weeks, depending on the case. Typical reasons are planning of network investments and customer complaints. At primary substations voltage levels are controlled continuously. The systems for power quality data acquisition, storing and reporting are separate stand-alone applications, which have not been integrated as part of distribution automation concept.

At Tampere University of Technology there is going on a project on power quality data management. One target of the project is to define power quality monitoring functions as a part of integrated distribution automation. Distribution automation opens new possibilities for continuous power quality monitoring.
For example, modern protection relays and monitoring units or intelligent $\mathrm{kWh}$-meters include new functions to monitor power quality both at primary substation and secondary substation levels. The advanced computer systems of the control center with the open architecture makes it possible to integrate the power quality data with the normal network operation and planning processes.

To obtain information on how power quality varies simultaneously in different parts of networks and to compare the characteristics of different measurement devices some field measurements have also been made. One central target was to evaluate the importance of different points in the network when power quality monitoring is planned.

The development of systematic procedures for power quality data management supports in general:

- customer services (e.g. quality reports, clarifying customer requests, planning of compensation of reactive power, instructions for the use of various equipment),

- distribution network design (e.g. investment plans and management of voltage drops and fluctuations, harmonics and other disturbances),

- national statistics (e.g. outage statistics, needs of the Energy Market Authority).

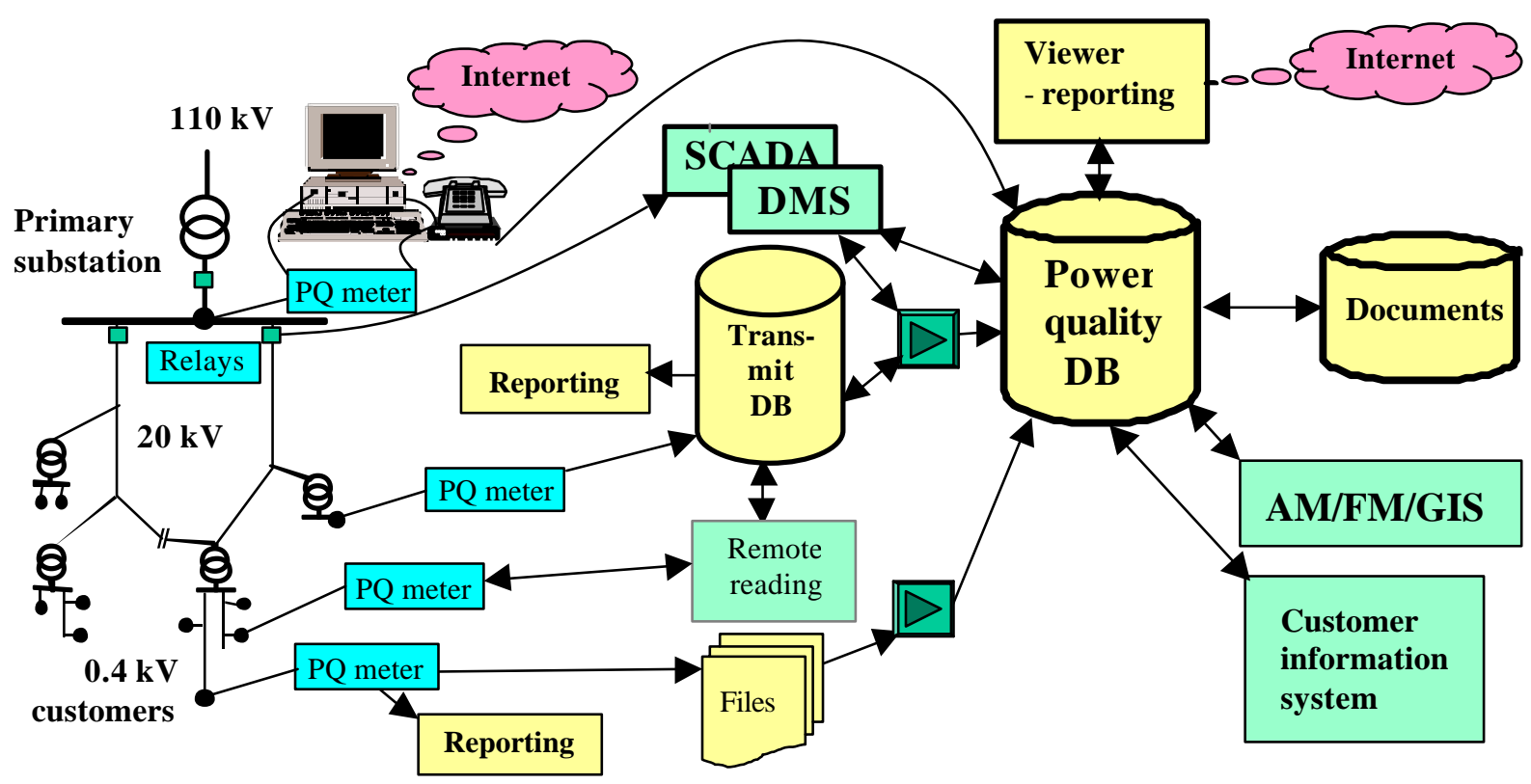

Fig. 1 The power quality data management system as part of integrated DA concept 


\section{POWER QUALITY MONITORING AS INTEGRATED WITH DISTRIBUTION AUTOMATION}

Antti Mäkinen, Marko Parkki and Pertti Järventausta

Tampere University of Technology, Finland
Markus Kortesluoma and Pekka Verho

ABB Substation Automation Oy, Finland
Seppo Vehviläinen

MX Electrix Oy, Finland
Reino Seesvuori

Tampere Power Utility, Finland
Aimo Rinta-Opas

Koillis-Satakunnan Sähkö Oy, Finland

\section{INTRODUCTION}

Requirements and expectations associated with power quality have been become increasingly important in our modern society. The quality of power distribution includes both power quality and quality of customer services. At the same time with the developments in distribution automation and the electricity market, many practices at electricity distribution companies are changing, and new possibilities and challenges are emerging.

According to the Finnish Electricity Market Act, the supply of electricity is faulty if the quality of electricity or the manner of supply does not correspond to what can be considered to be agreed upon. Unless otherwise agreed, the supply of electricity is faulty if the quality of the electricity does not correspond to the standards adhered to in Finland or if there have been continuous or repeated interruptions in the supply of electricity, and these interruptions cannot be considered minor when taking into account their reason and circumstances. Generally, the European standard EN 50160 'Voltage characteristics of electricity supplied by public distribution systems' is now applied at distribution companies.

The standard EN50160 gives the main characteristics of the supply voltage at the customer's supply terminals under normal operating conditions with regard to frequency, magnitude, wave form and symmetry of the three phase voltages. The quality quantities of EN 50160 are the basis for monitoring voltage quality resulting from the operations of the distribution company. However, for practical network planning distribution companies often use also some more strict planning levels. Statistics of interruptions are recorded both for distribution companies' own needs and for the Energy Market Authority. Fault statistics are important source information for network investment plans and for maintenance co-ordination.

Nowadays, in Finland power quality measurements are usually carried out temporarily, lasting from some few hours to some weeks, depending on the case. Typical reasons are planning of network investments and customer complaints. At primary substations voltage levels are controlled continuously. The systems for power quality data acquisition, storing and reporting are separate stand-alone applications, which have not been integrated as part of distribution automation concept.
At Tampere University of Technology there is going on a project on power quality data management. One target of the project is to define power quality monitoring functions as a part of integrated distribution automation. Distribution automation opens new possibilities for continuous power quality monitoring. For example, modern protection relays and monitoring units or intelligent $\mathrm{kWh}$-meters include new functions to monitor power quality both at primary substation and secondary substation levels. The advanced computer systems of the control center with the open architecture makes it possible to integrate the power quality data with the normal network operation and planning processes. When some abnormal quantities are identified by continuous on-line monitoring, more detailed measurements with advanced measurement equipment can be done at specific network points or at customers.

\section{POSSIBILITIES OF POWER QUALITY MONITORING USING DISTRIBUTION AUTOMATION}

\section{Protection relays, SCADA and DMS}

Modern protection relays and monitoring units include new functions to monitor power quality both at primary substation and secondary substation levels. The more advanced use of protection relays enables also more detailed disturbance statistics. For example, voltage dips might be registered directly or they can be analysed based on measured short-circuit currents. A disturbance recorder function can be triggered automatically to record current and voltage waveforms whenever needed.

Voltage level, voltage unbalance, frequency etc. are supervised in protection relays and monitoring units. Also still more sophisticated functions like harmonic analysis, voltage dips and swells, flicker etc. can be implemented to these units. There are already some units including basic power quality functions added to basic protection and monitoring functions.

Protection relays and monitoring units provide one part of power quality monitoring system, i.e. continuous measurements on-site. Utilisation of remote communication and SCADA system makes better use of the on-site measurements. This makes it possible to divide responsibilities in information measuring, storing and monitoring between units and SCADA system. Units focus on measuring and temporary storage of 
power quality data. In many cases the measuring unit cannot store large amount of data during a long period and communication cannot retrieve all the data needed for the analysis. Then power quality data can be recalculated and packed into indices or some intermediate storage and analysis system like station SCADA can be utilised. Network center SCADA system gathers data from units with cycles applicable with communication and stores data for later viewing in control center. This concept enables large power quality monitoring systems with several units. The concept also enables power quality data collection and evaluation with long time period. Laborious manual retrieval and handling of measurement unit data is now given for the automation system

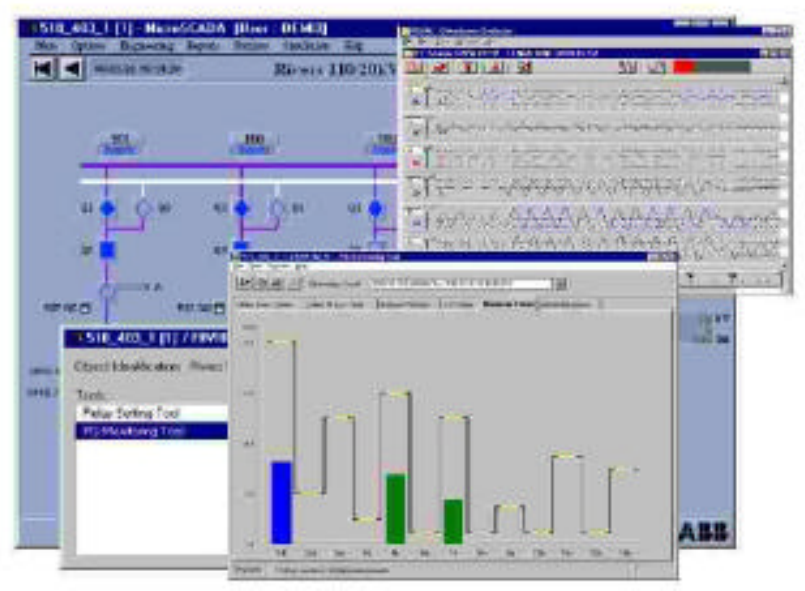

Fig. 1 A feeder terminal with views of disturbance recorder and power quality harmonics function in a SCADA system.

Distribution management system (DMS) is the center of integration putting together the real-time process information, network data and intelligent applications for normal state and fault management. The overall aim of the DMS is the minimisation of the operational costs (e.g. power losses, outage costs) subject to the technical constraints (e.g. voltage level, thermal limits, the operation of protection). The DMS presents the realtime electrical state of the distribution network on the geographical user-interface. It can inform the operator of various abnormalities (e.g. faults, voltage drops, overloadings) and propose necessary actions. In everyday use the operator can study the real state of the network or make investigations in a simulation state. [1] DMS also offers a way to incorporate the power quality monitoring with the network data.

\section{Advanced kWh-meters}

Quality Guards are are fairly cheap smart kWh-meters with power quality monitoring functions [2]. Usually both power quality data and also data on powers or currents are registered. The recording density can be set as some seconds, minutes or hours. The usual Quality Guard is able to meter the following quantities for each of the three phases: voltage and current variations, active power, apparent power, total reactive power (according to Fryze), fundamental frequency reactive power, total harmonic distortion of the supply voltage (THD), DC-voltage component, frequency of the supply voltage and voltage unbalance between the three phases.

The simplest version of the Quality Guard records only aforementioned powers and voltage and current variations. The most versatile recent version register also six most important harmonic voltages and voltage dips. Quality Guards can be used for temporary and continuous measurements with on-site or remote reading possibilities and can also concurrently function as revenue meters if desired. They can be used also at primary substation and secondary substation levels.

In the future several possible additional functions can give rather remarkable additional value for continuous measurements with data transmission possibilities. Some examples are: transmission of the state of short circuit and earth fault indicators, monitoring of temperatures (e.g. for evaluation of ageing of transformers), alarms, control commands for devices, indication of broken conductors.

\section{EXAMPLES OF COMMON POWER QUALITY MONITORING PRACTICES IN URBAN AND RURAL DISTRIBUTION COMPANIES}

\section{Tampere Power Utility - an example of an urban company}

Tampere Power Utility is an Finnish urban distribution company with about 117000 customers. The reliability of the Utility's power supplies to Tampere is fairly high. and average annual blackout times for consumers have been about 20 minutes in recent years.

In past years Tampere Power Utility has been concentrated rather strongly especially on temporary power quality monitoring and it has fairly long experience both in power quality and disturbance measurements. Several different kinds of power quality meters are used, e.g. MXPQKML (product name 'Laatuvahti' or 'Quality Guard' supplied by Mittrix Oy, nowadays MX Electrix Oy, Finland), Memobox 686, Memobox 800; BMI 8020, Dranetz PP1, Dranetz 4300, Dranetz 658 and Dranetz 656A. Under some disturbance circumstances also devices for magnetic field measurements are applied. Power quality measurements are carried out temporarily, lasting usually from some few hours to some weeks, depending on the case. Only at primary substations voltage levels are controlled continuously. Most frequently Quality Guards are used for temporary measurements. If more information e.g. on individual harmonics or on flicker severity is needed then more versatile power network analysers are used. Nowadays the information related to the power quality is collected in separate files or databases. 


\subsection{Koillis-Satakunnan Sähkö Oy - an example of an rural company}

Koillis-Satakunnan Sähkö Oy is a medium-size Finnish rural distribution company with about 14000 customers. The total delivery of energy by the utility is about 160 $\mathrm{GWh}$ and the peak power about $43 \mathrm{MW}$. Most of the distribution is in rural areas with about $1500 \mathrm{~km}$ of medium voltage (MV) lines, $50 \mathrm{MV}$ feeders, 1,000 distribution substations $(20 / 0,4 \mathrm{kV})$ and about 600 line disconnectors, of which 100 are remote controlled.

The main focus in the sense of power quality has been previously in the availability (i.e. number and length of interruptions) and overall voltage level, as normally with rural companies. For example, the annual mean outage time of the distribution substations per fault has decreased about $50 \%$ in the past 10 years by using distribution automation and fault location systems.

In addition to the voltage variations and interruptions the other voltage characteristics has not been a common problem so far. However, more attention has recently been given to power quality monitoring. Most interesting issues are voltage variations and voltage dips. Efforts to decrease number of interruptions are also now topical e.g. by maintaining of the wayleaves of lines, shielding live parts against animals and branches at distribution substations and by changing to resonant earthed MV systems. At present the company has installed some power quality meters (Quality Guards) along the network for temporary and continuous measurements to improve the voltage level monitoring.

\section{THE CONCEPT OF THE POWER QUALITY DATA MANAGEMENT SYSTEM INTEGRATED WITH DISTRIBUTION AUTOMATION}

At Tampere University of Technology there is going on a project on power quality data management. One target of the project is to define power quality monitoring functions as a part of integrated distribution automation. The main ideas of the concept of the power quality data management system are presented in the Figure 3. The project extends the concept of integrated software tools for improving quality of supply presented in [1]. The basic idea in this concept is to combine power quality management as an essential part of comprehensive DA system. Usually the systems for power quality data acquisition, storing, and reporting are nowadays separate stand-alone applications, which have not been integrated as part of DA concept [3], [4].

The concept contains the interfaces which are related to the devices producing power quality data (the special meters, customer meters, protective relays, feeder terminals) and the interfaces which are related to the devices and systems which utilise power quality quantities (SCADA, distribution management system (DMS), customer information system). In addition to the measurement data also some explaining site information (network data, customer data) will also be stored and linked to the system. The power quality database may also contain the interface to the interruption database maintained by the distribution management system (DMS) and/or SCADA (e.g. including statistics on autoreclosing occurrences). Accordingly all the disturbances which have appeared in the distribution can be examined as one wholeness.

One task in the project has been to define the power quality database for power companies. The database serves as a databank to different functions (for example compensation studies, disturbance statistics) which are related to the quality of the electricity of the power company. The database will enable an efficient power quality information storage system with interfaces both to power quality measurement devices and to systems utilising quality data. The study will support management of the power quality including:

- power quality monitoring measurements

- power quality data acquisition and recording

- reporting of power quality

- utilising power quality data in the separate information systems and for network design

- storing the central quality data from temporary separate quality recordings for future needs

Distribution management system (DMS) gives possibilities to reach real time and stored power quality data by using the same familiar geographical userinterface as in other operations. Readings of meters can also be activated straight from here. Moreover, load data, states of fault indicators and several control possibilities are concurrently available. Measured data can be effectively utilised in order to make network calculations and analysis even more realistic.

The power quality database may also contain the interface to the interruption database maintained by the distribution management system (DMS) and/or SCADA (e.g. including statistics on autoreclosing occurrences). The DMS maintains data on all faults (temporary and permanent), maintenance outages, and non-delivered energy which can be studied for each customer.

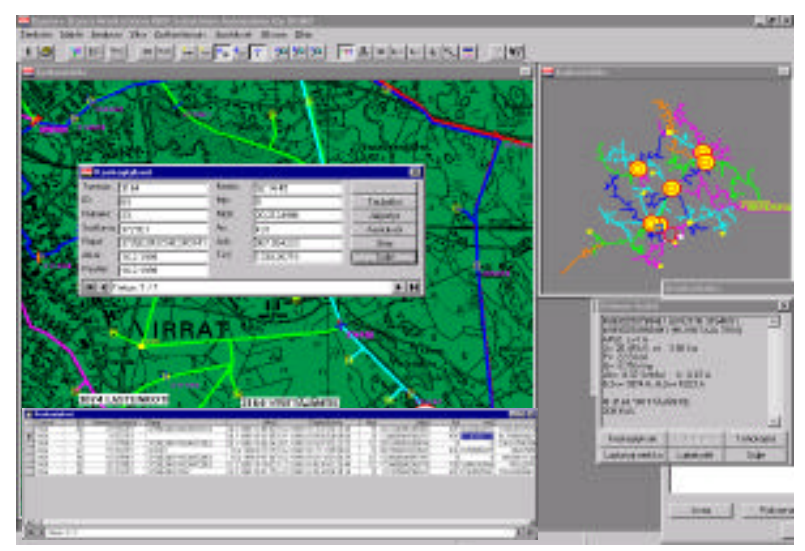

Fig. 2 A view of the interruption database of the DMS 


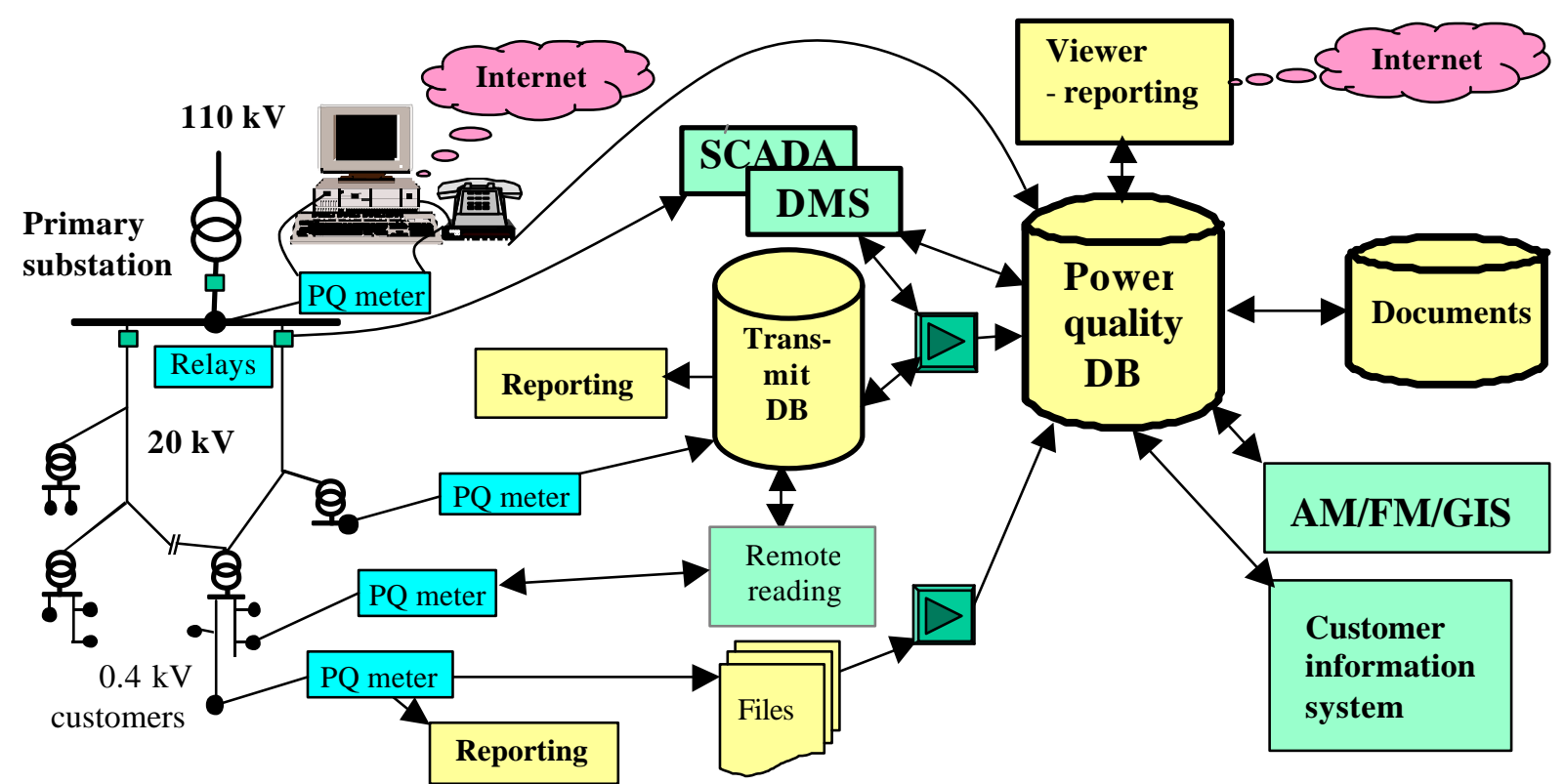

Fig. 3 The power quality data management system as a part of integrated DA concept.

So far the first demonstration application of the power quality database has been realised as open relational database. This application contains functions performed by the Excel spreadsheet and the MS Access database. Here, in this phase, only the customer- or site-specific measurements that have been performed with Quality Guard are dealt. The desired cumulated probability $(0,1,5,50,95,99$ and $100 \%)$ values of the powers, currents and power quality quantities are moved to Access database from which any selected values can be obtained as summaries and reports. In the demonstration application all the actual measurement data is stored as $10 \mathrm{~min}$ average values, too. One task in the project is to define how the data should be packed for long time storing. Reports can be based on Access inquiries and reports or on Excel functions. Targets of the reports are, for example, to enable both easy comparisons with the voltage quality standard EN 50160 or other recommendations and short or long time monitoring of the power quality quantities and the loads. An interface to the interruption database has also been demonstrated.

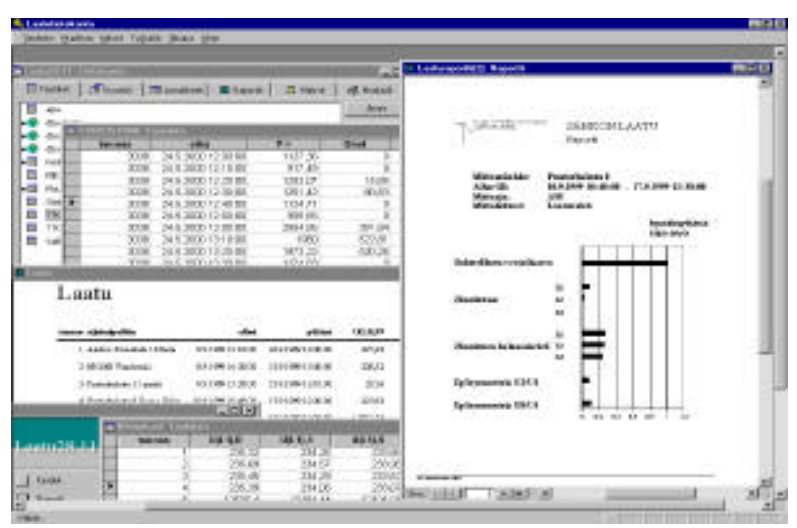

Fig. 4 A view to the content of the MS Access based power quality database application

\section{NETWORK STUDIES}

\section{Power quality variation along the network}

To obtain information on how power quality varies simultaneously in different parts of networks and to compare the characteristics of different measurement devices some field measurements have also been made. One central target was to evaluate the importance of different points in the network when power quality monitoring is planned.

In the urban network of Tampere Power Utility six sites from $110 / 20 \mathrm{kV}$ primary substation to LV customers were measured for one week and simultaneously at 10 minute intervals (mean values). Fig. 5 shows an example of how the total harmonic distortion of the supply voltage varied at different points of the network on a specific day. The changes of the voltage distortion depend both on varying loads and on automatic controls of compensation capacitors banks.

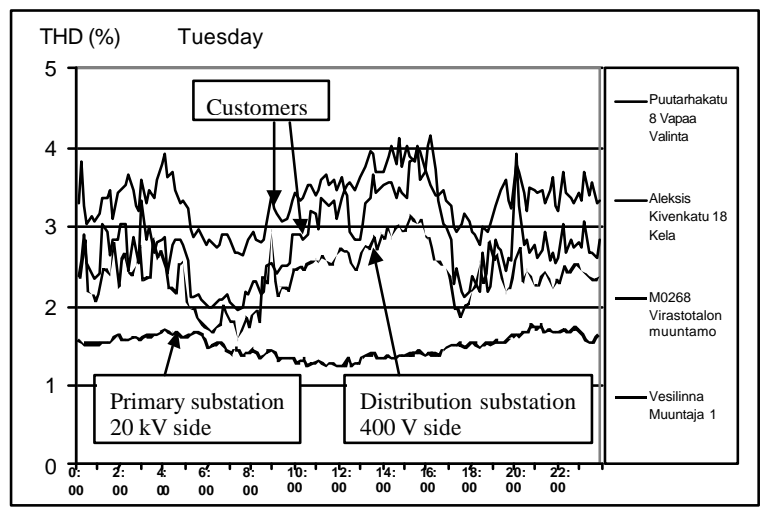

Fig. 5 Variations of the total harmonic distortion 


\section{Continuous power quality monitoring}

To obtain new experiences and data on continuous long time monitoring at secondary substation level a Quality Guard is mounted also at Tampere University of Technology at the $20 \mathrm{kV}$ MV connection point of the public power network. This quality meter can be read remotely via a modem or locally through a separate serial port. Measurement data is then stored in the power quality database for further processing. These kind of continuous measurements will probably extend in the foreseeable future.

Fig. 6 presents the voltage distortion (THD) during a seven months period. One zero value is caused by an half hour interruption and from other zero periods the registrations were not done for various reasons. This kind of long time monitoring gives obviously rather reliable basic data when we are interested in the highest values of THD. Here THD is at its highest level usually day by day in the late evening and nightly.

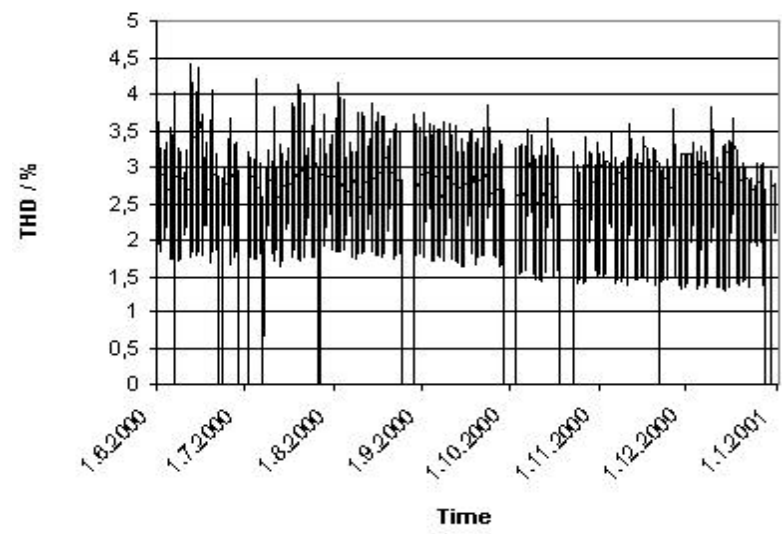

Fig. 6 Variation of total harmonic distortion (THD)

Evaluation of supply voltage dip disturbances at a rural area of Koillis-Satakunnan Sähkö Oy

The basic reasons for these studies were complaints about power quality at a smallish industrial plant. After some basic investigations voltage dips and short interruption were evaluated as most important problems. In order to get more information on the sensitivity of this industrial process network experiments by causing ten short circuits were carried out. In order to get more information on the sensitivity of process equipment and on network disturbances a continuous measurement using BMI8020 was set up at the feeding primary substation $(45 / 20 \mathrm{kV})$. Fig. 7 presents example data including about 100 voltage dips or short interruptions. Here for each disturbance the lowest value of the three phase to phase voltages is shown. This kind of quality data gives effectively support to find out the most appropriate actions both at the plant and in public distribution network. During studies this primary substation was also evaluated as a good pilot environment for the newest version of the Quality Guard which was mentioned earlier in this paper.

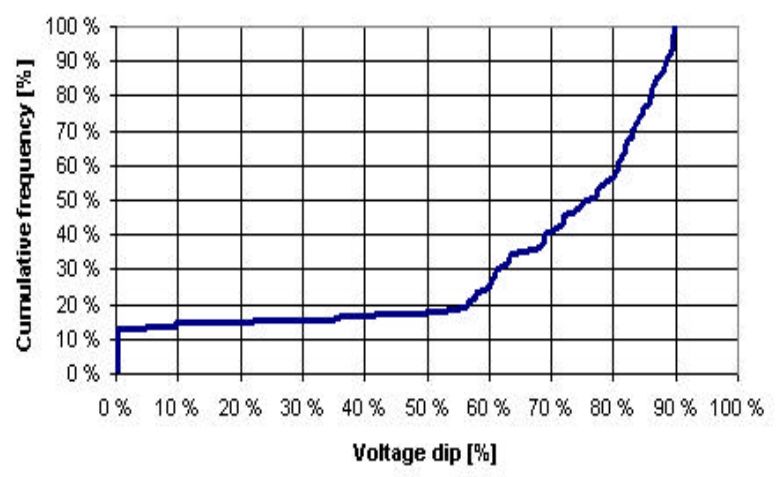

Fig. 7 Cumulative distribution of voltage dips and short interruptions

\section{CONCLUSIONS}

Distribution automation is one way to develop continuous power quality monitoring. At Tampere University of Technology there is going on a project on power quality data management. One target of the project is to define power quality monitoring functions as a part of integrated distribution automation and relating computer systems.

The development of systematic procedures for power quality data management supports in general:

- customer services (e.g. quality reports, clarifying customer requests, planning of compensation of reactive power, instructions for the use of various equipment),

- distribution network design (e.g. investment plans and management of voltage drops and fluctuations, harmonics and other disturbances),

- national statistics (e.g. outage statistics, needs of the Energy Market Authority).

\section{REFERENCES}

[1] Verho P., Järventausta P., Kärenlampi M., Partanen J., Rinta-Opas A., Improving quality of supply by integrated software tools. Proceedings of DistribuTECH '98 Europe. London, UK, October 1998, 12 p.

[2] Koponen P., Vehviläinen S., Rantanen J., Additional functions of remote read kWh-meters. Proceedings of DA/DSM Europe 94. Paris, France, September 1994, 9 p.

[3] Healy F., Integrated, communicating, power quality measurement system for power distribution systems. Proceedings of DistribuTECH '99 Europe. Madrid, Spain, September 1999, 9 p.

[4]Kennedy B.W., Sabin, D.D., Utilizing the internet for power quality reporting (2/w5). Proceedings of the $15^{\text {th }}$ International Conference on Electricity Distribution (CIRED '99), Nice, France, June 1999, pp.169-170. 